\title{
Effect of Surface Treatment on Tribological Behavior of Ti-6Al-4V Implant Alloy
}

\author{
B. K. C. Ganesh ${ }^{1 *}$, N. Ramanaiah ${ }^{1}$, P. V. Chandrasekhar Rao ${ }^{2}$ \\ ${ }^{1}$ Department of Mechanical Engineering, College of Engineering (Autonomous), Andhra University, Visakhapatnam, India \\ ${ }^{2}$ Department of Mechanical Engineering, L. B. R. College of Engineering, Vijayawada, India \\ Email: "bkcganesh@yahoomail.com
}

Received May 20, 2012; revised June 30, 2012; accepted July 15, 2012

\begin{abstract}
Titanium alloys are extensively used in various fields of engineering, medicine, aerospace, marine due to its excellent mechanical properties. Its usage is more pronounced today in the field of biomedical implants due to its superior biocompatibility, corrosive resistance and high strength to weight ratio. It has poor abrasive wear resistance due to high coefficient of friction and low thermal conductivity. Poor abrasive wear resistance results in the formation of wear debris at the implant area causing toxicity, inflammation and pain. Surface treatment of the implant alloy through heat treatment, application of protective coatings, introduction of compressive residual stresses by shotpeening and shot blasting are some of the methods to mitigate wear of the implant alloy. In this work Ti-6Al-4V implant alloy is treated under various conditions of heat treatment, shotpeening and shot blasting operations on a pin on disc wear testing machine. Shotpeening and Shot blasting are the operations usually performed on this alloy to improve fatigue strength and surface roughness. In this work the effect of above surface treatments were studied on the wear behavior of Ti-6Al-4V implant alloy and an improvement in the wear resistance of the alloy is reported. Scanning Electron micrograph (SEM) along with Energy Dispersive Spectrometry analysis (EDS) is done to authenticate the experimental results obtained during the wear testing procedure.
\end{abstract}

Keywords: Heat Treatment; Shotpeening; Wear Resistance; Sliding Velocity

\section{Introduction}

The bulk properties of biomaterials such as non-toxicity, corrosion resistance or controlled degradability, modulus of elasticity and fatigue strength have long been recognized to be highly relevant in terms of the selection of the right implant alloy. The events after implantation include interactions between the biological environment and artificial material surfaces, onset of biological reactions as well as particular response paths chosen by the body. The material surface plays an extremely important role in the response of biological environment to the artificial medical devices. The proper surface modification techniques not only retain the excellent bulk attributes of titanium and its alloys, such as low modulus, good fatigue strength, formability and machinability, but also improve specific surface properties such as wear and corrosive resistance [1].

Titanium has a good biocompatibility but it has a high coefficient of friction which results in poor abrasive wear resistance. The property of poor abrasive resistance is important in generating a wear debris, when the artificial

${ }^{*}$ Corresponding author. implant is in contact with the healthy and natural joint. The accumulation of wear debris causes inflammation, pain and finally loosening of the joint. Implant wear is a common phenomenon which is resulted due to high friction between artificial materials which is higher than that of healthy and natural joints. This high friction is attributed to the high rigidity of artificial materials leading to non-recoverable wear [2].

Wear resistance plays an important role whenever a material such as a bone plate for fracture fixation is attached to fractured bones of a different stiffness values and modules of elasticity. Relative movements between the two different materials such as bone, implant material and between the parts of multi-component systems will occur when a cyclic load is applied to the system. These relative movements causes a wear stress on the attachment devices (bone screws as well as on the eyelets). Therefore high wear resistance is required for orthopedic implants to obtain biocompatibility and acceptability [3].

The drawback of extensive use of titanium alloys in hip replacement and other artificial joints is poor tribological properties such as poor abrasive, poor fretting behavior and high coefficient of friction. The improve- 
ment of the above properties can be done with the help of four main mechanisms as suggested by Zhecheva et al. [4]. They are as follows:

1) To induce a compressive residual stress;

2) To decrease the coefficient of friction;

3) To increase the hardness;

4) To increase the surface roughness.

Mitsuo [5] reported that the application of stress by rapid quenching results in the formation of martensitic structure in steels which contain residual austenite in their microstructures. This phenomenon is called stress or strain induced martensitic transformation which enhances ductility or fracture toughness of steel. Deformation induced martensitic transformation also occurs in titanium where unstable beta phase is retained at room temperature by rapid cooling such as water quenching from a high temperature near the beta transus temperature. The formation of this martensitic structure or transformed beta is important in improving the hardness of the alloy by which the implant wear can also be minimized.

The surface modification and change in microstructure can be obtained by heat treating the various samples at beta transus temperature, (transformation temperature) where primary $\alpha$ changes from hexagonally closely packed crystallographic structure $(\alpha)$ to body centered cubic crystallographic structure $(\beta)$. These specimens were subsequently cooled by rapid quenching by water, cooling in the furnace and air, followed by aging of these alloys at $500^{\circ} \mathrm{C}$ for a period of one hour. The objective of conducting the heat treatment cycle is to improve the hardness of the alloy which is beneficial in increasing the wear resistance of the alloy by retaining the transformed beta at the room temperature. The introduction of compressive residual stresses in the surface layer by surface modification technique such as shotpeening, shot blasting and ion-beam enhanced deposition etc. also mitigate the wear of implant material [6].

Wear rate calculation by pin and rotating disc machine using weight loss method is one of the common techniques to evaluate dry sliding wear behavior of titanium implant materials. A. Molinari et al. [7] investigated on dry sliding wear mechanism of Ti-6Al-4V alloy. In their experimental work it has been found that the wear volume of the rotating specimens is reported as a function as sliding speed and the load applied on the pin. An increase in wear volume is resulted with an increase in applied load. O. Alam et al. [8] in their experimental work of dry sliding wear on Ti-6Al-4V alloy have reported that under a constant load of $45 \mathrm{~N}$ applied on pin, an increase of wear rate was identified up to a sliding distance of 500 meters. There after a steady state is attained during which no appreciable change in the wear rate behavior of the alloy was observed. S. J. Li et al. [9] had conducted experimental analysis on wear testing of Ti-6Al-4V alloy on various disc materials such as steel, Ultra high molecular weight polyethylene (UHMWPE) and bone of pig to represent actual working of the pin material in realistic operating environment. His experimental results indicate a decreasing trend in wear volume of the implant, while working on steel disc to UHMWPE and bone of pig. The results further concluded that irrespective of the disc material used, wear volumes reported are similar with respect to a change in various process parameters such as type of heat treatment, increase in the sliding velocity etc. Therefore in this experimental set up steel disc is only used as disc material and the results are reported.

\section{Materials and Methods}

The implant material is procured from South Asia Metal Corporation, Mumbai. The chemical composition by weight of the metals are as follows: $89.6 \%$ Titanium, $6.29 \%$ Aluminium, $3.95 \%$ Vanadium, $0.09 \%$ Iron, $0.029 \%$ Carbon.

The implant alloys are heat treated at above transformation temperature $\left(950^{\circ} \mathrm{C}\right)$ for one hour in an argon controlled atmosphere. One set of specimens were subjected to shotpeening operation at 4.5 and 3.5 bar pressure respectively. Another set of specimens were subjected to shot blasting for duration of 5 to $20 \mathrm{~min}$ at a pressure of 4.5 bar. The pins were cut according to the standard dimensions as shown in the Figure $\mathbf{1}$ for the evaluation of wear behavior. Scanning Electron Micrograph (SEM) analysis is also conducted to study the wear

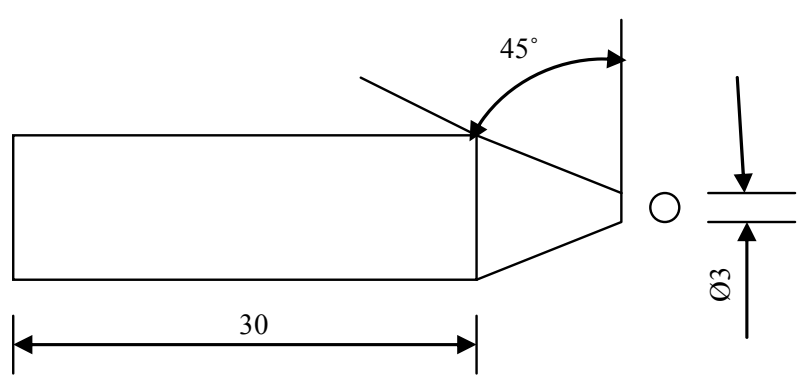

(a)
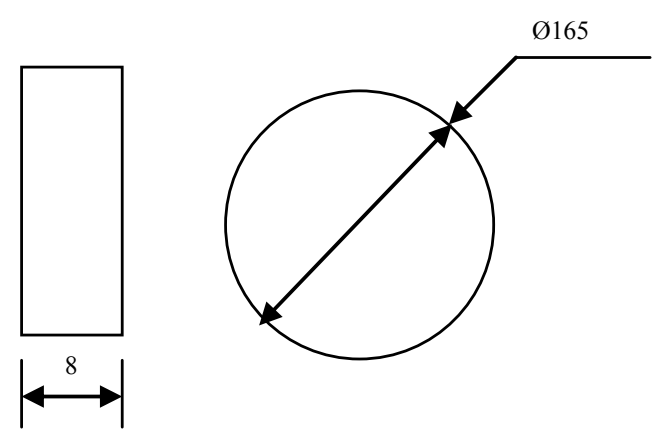

(b)

Figure 1. Dimensions of the (a) friction pin; (b) rotating disc in millimeters. 
track behavior of various heat treated specimens. Hardness values are measured by Vickers micro hardness testing machine at a constant load of $0.5 \mathrm{~kg}$. Average surface roughness $(\mathrm{Ra})$ value of the surface treated specimens was measured by Mitutayo surface roughness testing instrument.

The shot peening operation was performed according to the MIL-13165 standards. The various shot peening parameters are given under: type of shot: S230, material of shot: steel shot, angle of projection: $90^{\circ}$, diameter of shot: $0.6 \mathrm{~mm}$, duration of peening: $30 \mathrm{~min}$, coverage area: $100 \%$. The various shot blasting parameters are: type of grit: G80, material of the grit: steel grit, distance from nozzle to work piece: $30 \mathrm{~mm}$, angle of projection: $90^{\circ}$. All the treated specimens were tested for wear behavior by TR-20LE Ducom wear testing machine at a constant velocity of $1 \mathrm{~m} / \mathrm{sec}$ and with a sliding distance of 500 metres. Wear rate is calculated on the basis of volume of the material removed before and after conducting the wear test.

Loads acting on human joint vary considerably from joint to joint. For a particular joint, it varies with time during the loading cycle [10]. It has been reported that stresses in the living area are of the order of $1 \mathrm{MPa}$. Gispert et al. [11] used a normal pressure of $0.88 \mathrm{MPa}$. In this work a load of $50 \mathrm{~N}$ with a pin diameter of $10 \mathrm{~mm}$ is used to obtain a pressure of $0.7 \mathrm{MPa}$ which is considered to be safe stress acting on the joint during the loading conditions.

\section{Results and Discussion}

\subsection{Wear Track Analysis}

The following Figure 2 shows the wear track micrographs of alloy when subjected to heat treatment and shot peening operations. It is evident from the microstructures that the alloy Ti-6Al-4V (hereafter referred as Ti64) has the presence of a protective layer in its water quenched and air cooled specimens. The presence of this layer is only seen when the alloy is cooled at a faster rate such as water quenching and air cooling. This layer cannot be seen in the specimen which is subjected to slow cooling of the alloy in a furnace. Figure $\mathbf{3}$ shows the scanning electron micrograph (SEM) of water quenched specimen shown in Figure 2(b). The energy dispersive spectrometry (EDS) of the base and water quenched specimen is shown in Figure 4.

From the EDS analysis of the base wear specimen it is clear that the oxygen and carbon content are limited to 0.56 and 2.34 percentage by weight respectively. But when the specimen are heat treated above the beta transus temperature and quenched with water there is a formation of a protective layer as can be seen from the Figure 3. The EDS analysis of the protective layer shows

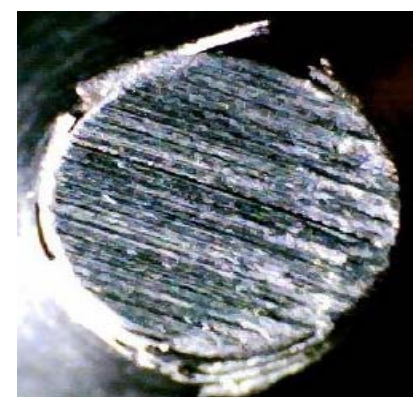

(a)

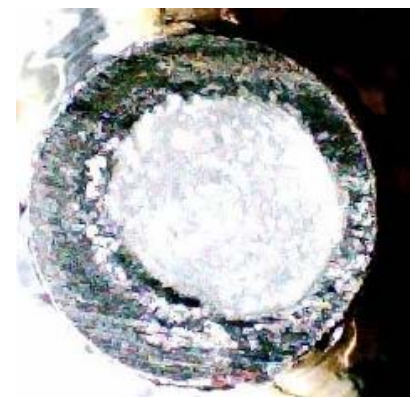

(c)

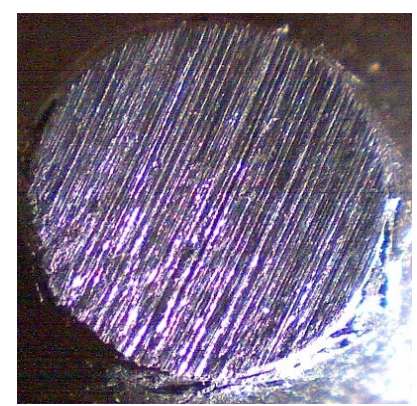

(e)

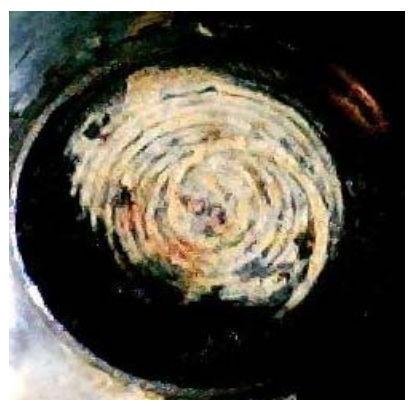

(b)

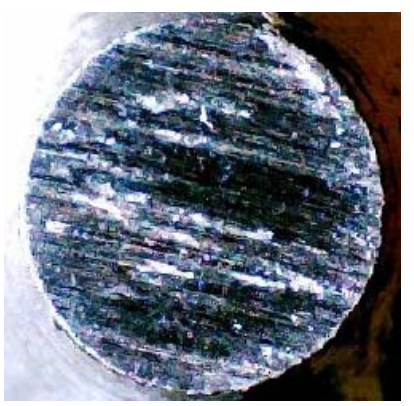

(d)

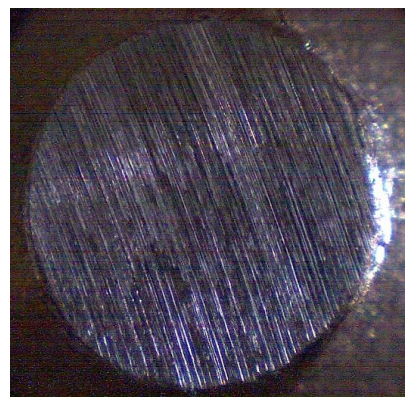

(f)
Figure 2. Wear Track of Ti-6Al-4V subjected to various heat treatment processes and shotpeening operations at $20 \times$ magnification. (a) Base material; (b) Water quenched; (c) Air cooled; (d) Furnace cooled; (e) Shotpeened at 4.5 bar; (f) Shotpeened at 3.5 bar.

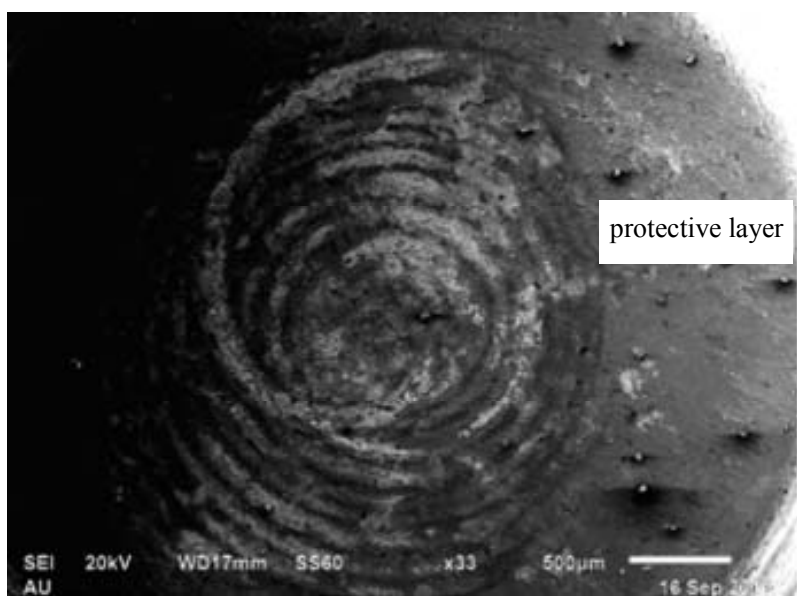

Figure 3. Scanning electron micrograph of water quenched wear specimen. 


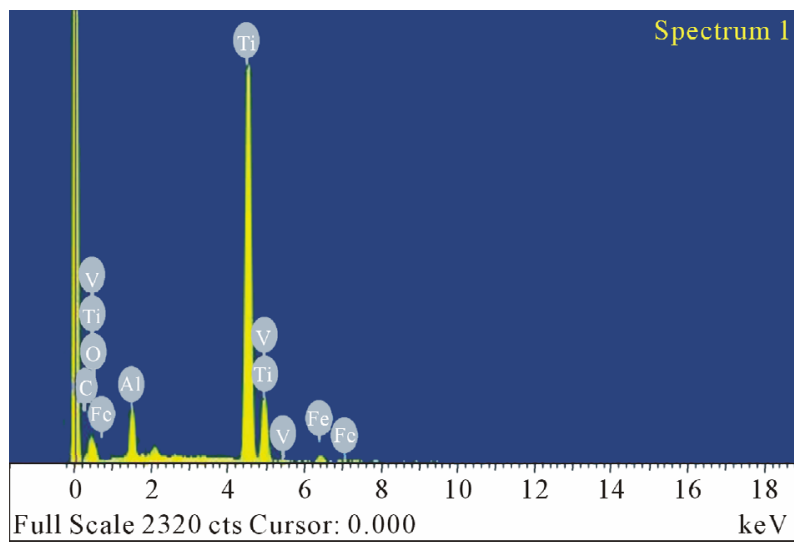

\begin{tabular}{ccc}
\hline Element & Weight\% & Atomic\% \\
\hline C K & 0.56 & 2.10 \\
O K & 2.34 & 6.53 \\
Al K & 1.79 & 2.96 \\
Ti K & 90.36 & 84.13 \\
V K & 4.41 & 3.86 \\
Fe L & 0.53 & 0.83 \\
& & 100 \\
\hline
\end{tabular}

(a)

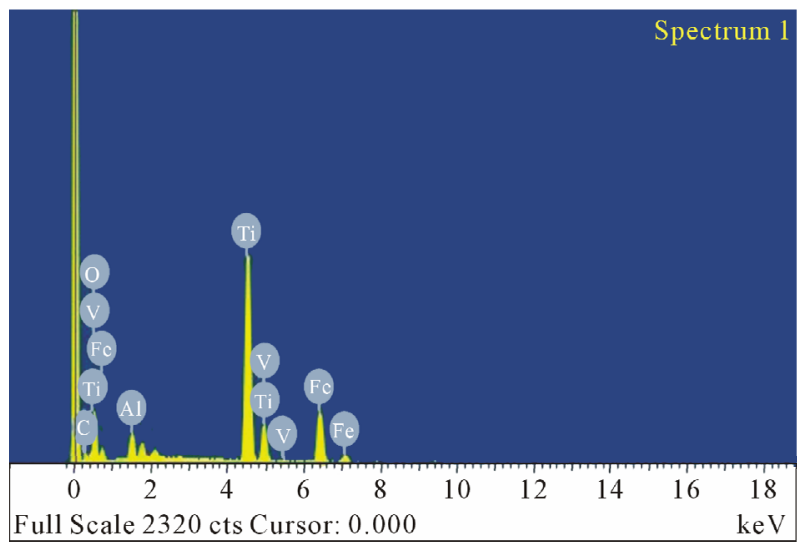

\begin{tabular}{ccc}
\hline Element & Weight\% & Atomic\% \\
\hline C K & 1.11 & 3.49 \\
O K & 12.14 & 28.57 \\
Al K & 1.60 & 2.24 \\
Ti K & 71.47 & 56.19 \\
V K & 4.30 & 3.18 \\
Fe L & 9.38 & 6.32 \\
$\quad$ Total & & 100 \\
\hline
\end{tabular}

(b)

Figure 4. (a) EDS analysis of base wear specimen; (b) EDS analysis of protective layer. high amount oxidation with its weight $\%$ at 12.14 and carbon percentage of $1.11 \%$ as shown in Figure 4(b). Further the EDS analysis of the some portion of the protective layer also indicates a higher amount of metal to metal contact with increasing percentage of iron content when in contact with the steel disc. It is evident from the literature that when titanium and its alloys are exposed to oxygen containing atmosphere it results in the formation of an oxide layer on its surface with an oxygen diffusion zone beneath it [12]. This formation is more pronounced when the alloy is heat treated above transformation temperature and cooled rapidly in air or quenching by water. This formation further plays an important role in developing a protective layer which promotes remarkable advantage of the alloy while working in a friction and wear environment. The presence of protective layer is crucial in improving corrosive and wear resistance. Further the scanning electron micrograph of quenched specimen given in Figure 5 show the presence of acicular martensitic structure $(\alpha)$ in white globular primary $\alpha$ and $\beta$ matrix. The presence of needle like acicular alpha greatly improves the hardness values of the quenched specimen. The microstructures have been consistent with respect to the work done on this alloy by A. K. Jha et al. [13] and A. Molinari et al. [6].

On the other hand the hardness of both the shotpeened and shot blasted materials have increased drastically during these surface treatment operations due to which the wear resistance of the treated specimens had increased twice to that of the untreated base specimen. But, it does not in any way correlate to the wear resistance obtained by the heat treated specimens. A very high amount of wear resistance is only possible with the development of a protective layer as can be seen in water quenched and air cooled specimens. It is evident from the graphical data presented in Figure 6 that the friction coefficient values of the shotpeened specimens have reduced

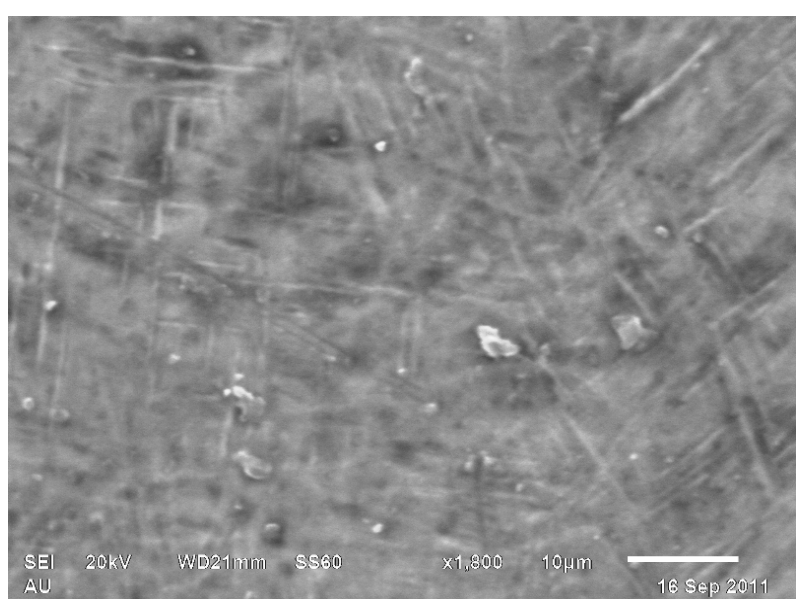

Figure 5. Scanning electron micrograph of quenched specimen. 


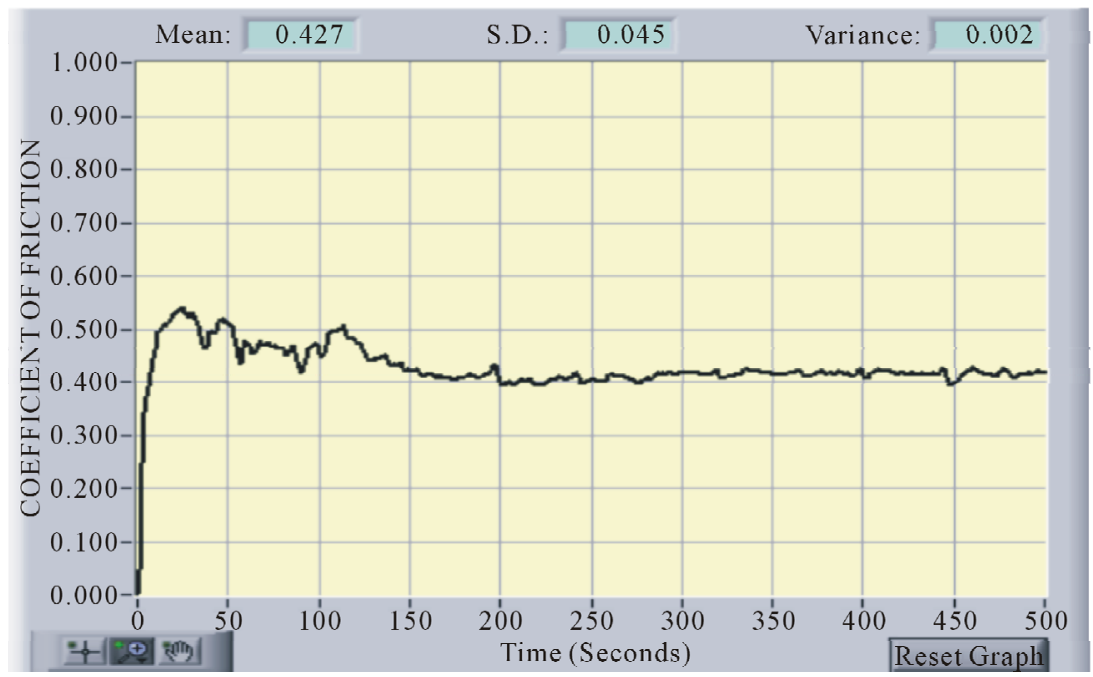

(a)

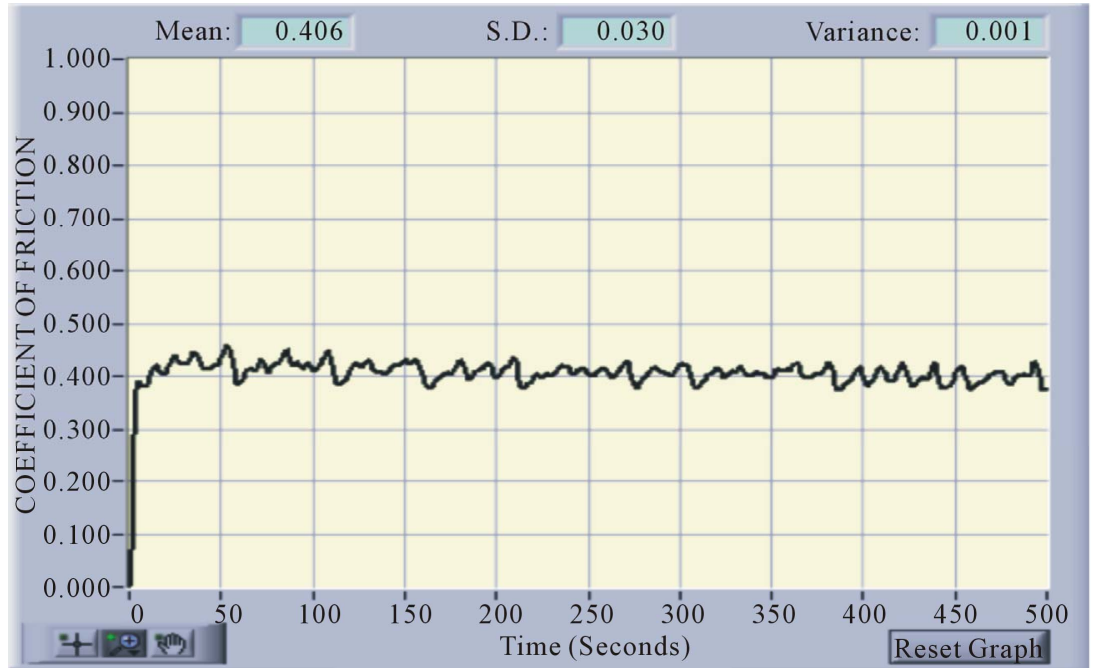

(b)

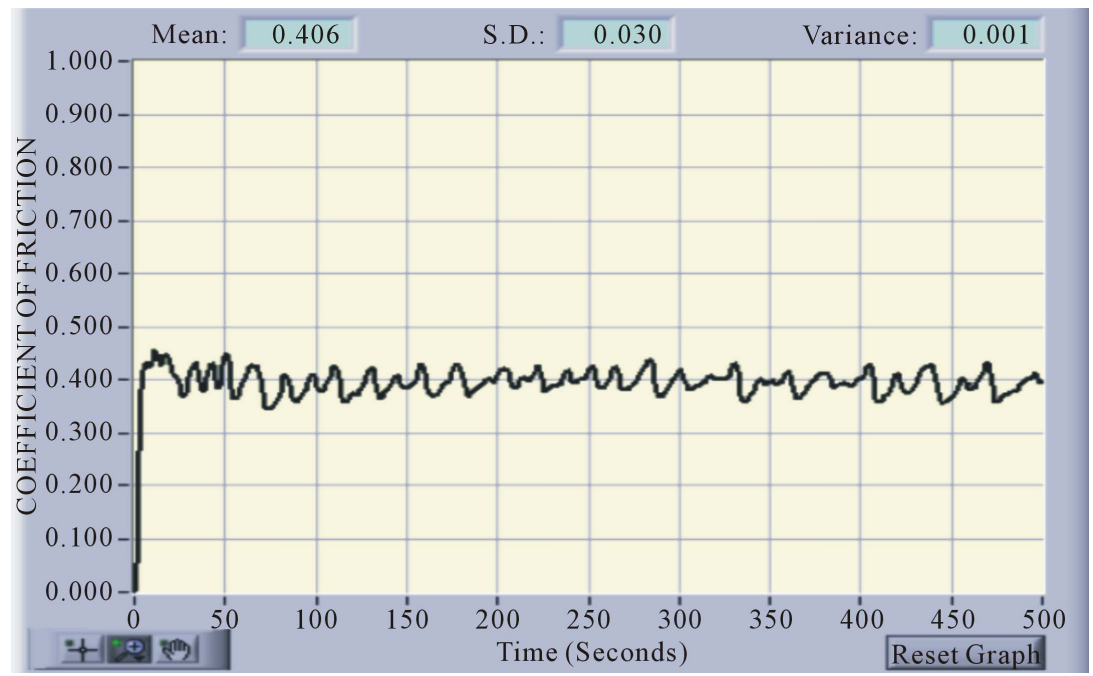

(c)

Figure 6. Graphs showing values of coefficient of friction vs time at various conditions. (a) Heat treated at $950^{\circ} \mathrm{C}$; (b) $\mathrm{Shot}-$ peened at 3.5 bar; (c) Shotpeened at 4.5 bar. 
to a large extent limiting the value to around 0.39 when compared to heat treated specimen with a value of 0.42 . This clearly indicates that the introduction of compressive residual stress into the base specimens by virtue of shot peening increased its hardness on the surface layer as can be seen from Table 1. Shot blasting for a lower duration had also decreased the friction coefficient to 0.37. This is due to the formation of a thin superficial layer which had developed a greater amount of resistance to indentation.

\subsection{Weight Loss and Wear Rate Analysis}

Maximum amount of weight loss has been reported from as received material as shown in Figure 7, where as less amount wear is reported from both water quenched and air cooled specimens of Ti64 alloy. The results commensurate with the hardness values and microstructure behavior of all the heat treated specimens. Similarly shorter duration of blasting and higher peening pressures in peening had resulted in obtaining higher wear resistance and surface roughness of the alloy while compared to the base material. Increase in the surface roughness of the alloy results in improved bio-adhesion and better Osseo-integration between the bone and implanted material [14].

Presence of high amount of wear is reported from the wear testing of as received material Ti64 alloy as shown in Figure 8. This corresponds to low hardness value where the value of vickers hardness number is only VHN 311 as compared to quenched specimen which is having a hardness value of VHN 380. High amount of hardness values in quenched specimen is due to the presence of acicular $\alpha$ (martensitic structure) which has been formed due to the heat treatment above beta transus temperature followed by water quenching and aging. The wear rate as shown in Table $\mathbf{1}$ is also high as in the case of as received material when compared to air cooling or water quenched specimens. The wear rate of furnace cooling specimen is greater than the water quenched and air

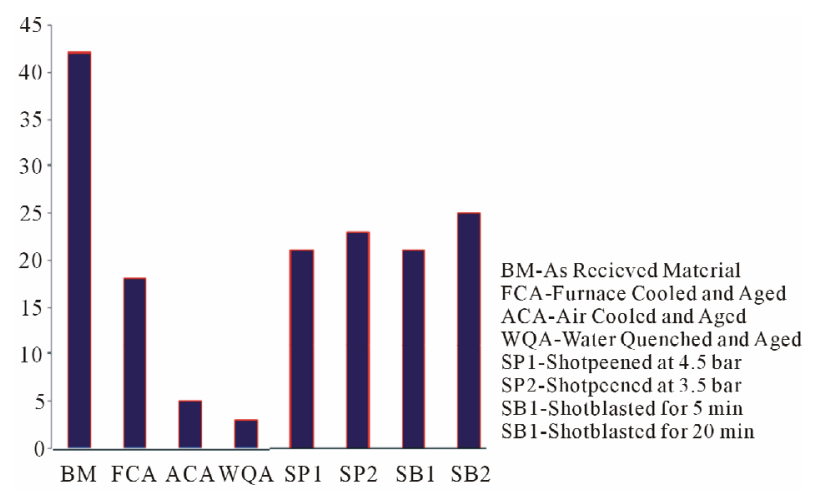

Figure 7. Weight loss of Ti-6Al-4V under various surface treated conditions. cooled specimens due to the formation of lamellar $\alpha$ plate like structure where there is no presence acicular $\alpha$ or retained beta. This is due to slow cooling of the specimen where complete transformation of body centered cubic crystallographic $(\beta)$ structure to hexagonally closely packed $(\alpha)$ structure has taken place, which indicates high strength due to its lamellar microstructure and also due to high aspect $(c / a)$ ratio of hexagonally packed crystallographic structure.

An improvement in the wear resistance the alloy when subjected to shot peening and blasting is reported in Figure 9. Shot peening is basically an operation intended to improve fatigue strength of the implant alloy by the induction of compressive residual stresses. In this experimental work it had been proved that application of higher amount of peening pressure had resulted in obtaining higher amount of surface hardness as well as a higher surface roughness value. This improvement in hardness had played an important role in minimizing the wear rate and improving the wear resistance of the implant alloy. Similarly shot blasting for a shorter duration of time had resulted in obtaining higher wear resistance of the alloy.

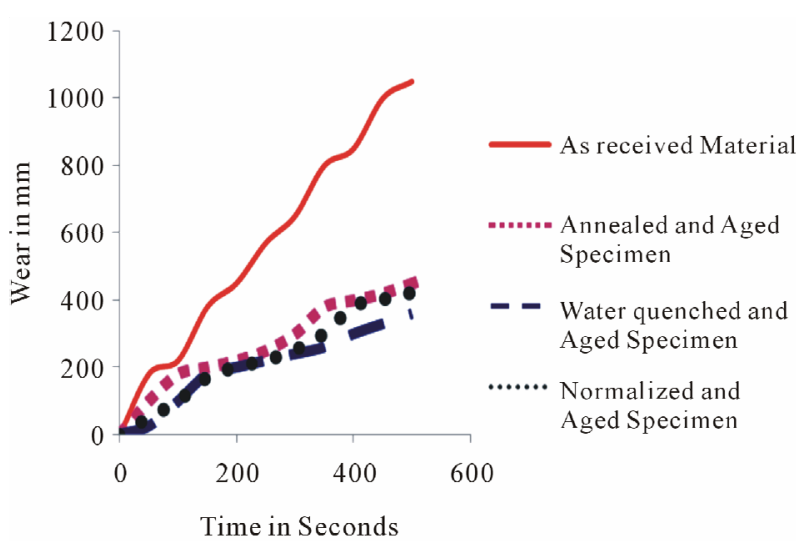

Figure 8. Wear behaviour of Ti-6Al-4V subjected to solution treatment and aging.

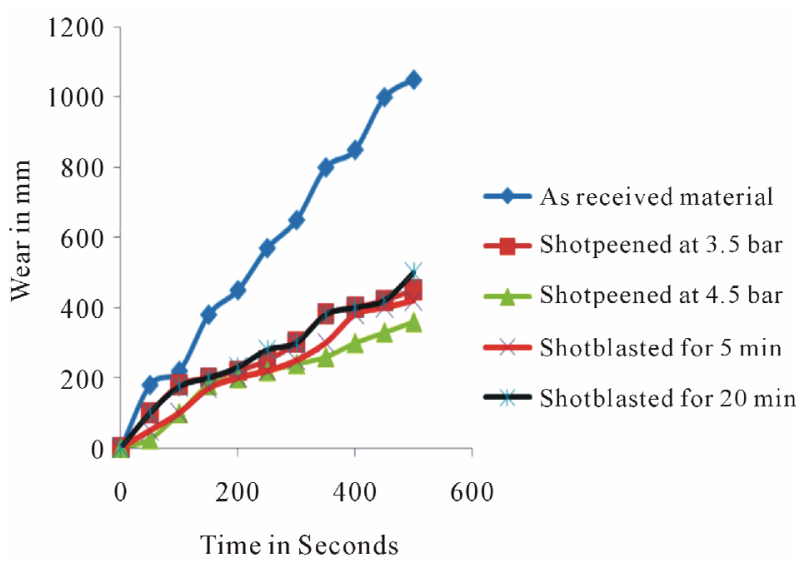

Figure 9. Wear behaviour of Ti-6Al-4V alloy subjected to shot peening and shot blasting operations. 
Table 1. Wear properties of Ti-6Al-4V subjected to various surface treatments.

\begin{tabular}{|c|c|c|c|}
\hline Type of Surface Treatment & Surface Roughness (Ra) & Micro Hardness (HV 0.5) & Wear Rate $\times 10^{-11} \mathrm{~m}^{3} / \mathrm{m}$ \\
\hline \multicolumn{4}{|c|}{ Ti-6Al-4V heat treated } \\
\hline As received (base metal) & 0.014 & 311 & 1.954 \\
\hline Furnace cooled and aged & 1.29 & 351 & 0.93 \\
\hline Air cooled and aged & 0.858 & 340 & 0.186 \\
\hline Water quenched and aged & 1.411 & 380 & 0.139 \\
\hline \multicolumn{4}{|c|}{ Ti-6Al-4V shotpeened } \\
\hline Shotpeened at 4.5 bar & 1.634 & 380 & 0.837 \\
\hline Shotpeened at $3.5 \mathrm{bar}$ & 1.62 & 383 & 0.976 \\
\hline \multicolumn{4}{|c|}{ Ti-6Al-4V shotblasted } \\
\hline Shotblasted for $5 \mathrm{~min}$ & 0.015 & 359 & 0.814 \\
\hline Shotblasted for $20 \mathrm{~min}$ & 0.013 & 350 & 0.956 \\
\hline
\end{tabular}

Blasting for a shorter duration had developed a superficial layer on the specimen which had inhibited the process of wear. Continuation of blasting for longer duration had resulted the merging of the superficial layer with substrate layer due to which there is a lesser amount of resistance to indentation and hence a comparatively higher wear rate. Therefore it can be summarized that though the surface treatment operations like shot peening and blasting might not yield a higher wear resistance as compared to that of the heat treated specimens, but they have their own importance in enhancing some of the important properties like fatigue strength, Osseo-integration and better wear resistance during its actual loading environment.

The improvement of wear resistance of all the surface treated specimens correlates the archard adhesive wear theory which states that if all junctions have the same diameter and if the real area of contact is given by the normal load "L" divided by the hardness " $H$ ", the total volume of the material "V" removed during sliding through a distance " $\mathrm{S}$ " is given by

$$
\mathrm{V}=\mathrm{k} * \frac{\mathrm{LS}}{3 \mathrm{H}}
$$

where " $\mathrm{k}$ " is the wear constant which gives the probability that a wear particle will be formed from an asperity junction. It is understood from the above equation that the hardness of the specimen is inversely proportional to the weight loss or volume of the material removed. Therefore Ti64 specimens show a proportional decrease in their wear rate with a significant increase in their hardness values.

\subsection{Effect of Sliding Velocity}

High amount of wear resistance is obtained when the sliding velocity of the alloy pin is subjected to an increased sliding velocity of $2 \mathrm{~m} / \mathrm{sec}$ instead of $1 \mathrm{~m} / \mathrm{sec}$, with all the remaining parameters kept constant. The wear resistance almost improved in parallel to the quenched specimen. This improvement is due to delamination wear of the material when the sliding velocity is increased. Type of wear at lower sliding velocity happens to be oxidative wear as shown in Figure 10(a), where as ploughing or severe plastic deformation has taken place in the form of delamination as shown in Figure 10(b). The delamination of the alloy has taken place due to following reseaons:

During wear, dislocations are generated in the material due to the plastic deformation of the surface by the slider. If an oxide layer is present it is broken by the passage of the slider thus exposing a fresh clean surface. This then allows those dislocations nearly parlell to the surface to be eliminated due to the action of stress at the free surface. With continued sliding there will be pile up of dislocations at finite distance from the surface which will lead to the formation of voids. When these voids coalese crack formation takes place. when the crack reaches a critical length the material between the crack and the surface will shear producing a sheet like particle.

This eventual presence of delaminated regions play an important role in minimising the loss of material due to coldworking or plastic deformation which had occurred when a soft material such as alloy pin material is incontact with the hard disc material.

\section{Conclusions}

1) The wear rate of quenched specimen is very low due to the presence of protective oxide coating layer formed during heat treatment and also due to the presence of acicular martensitic structure (retained beta) in its 


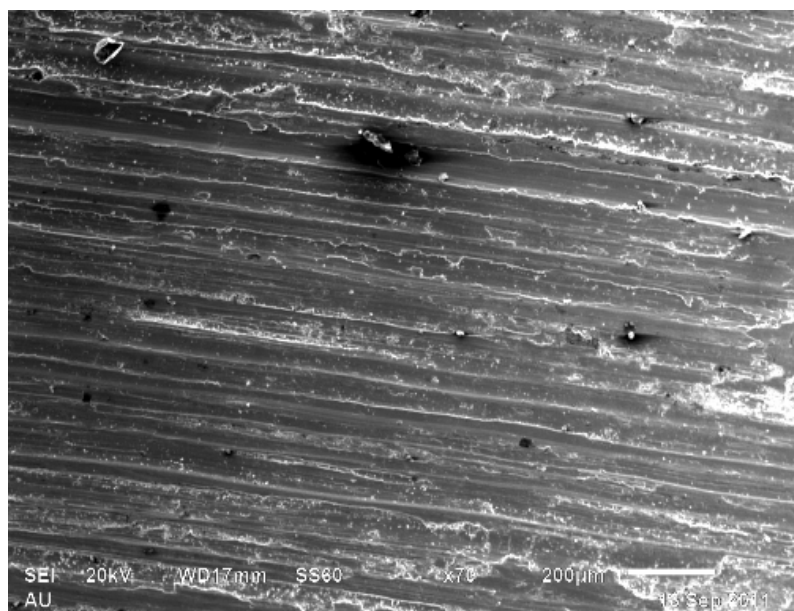

(a)

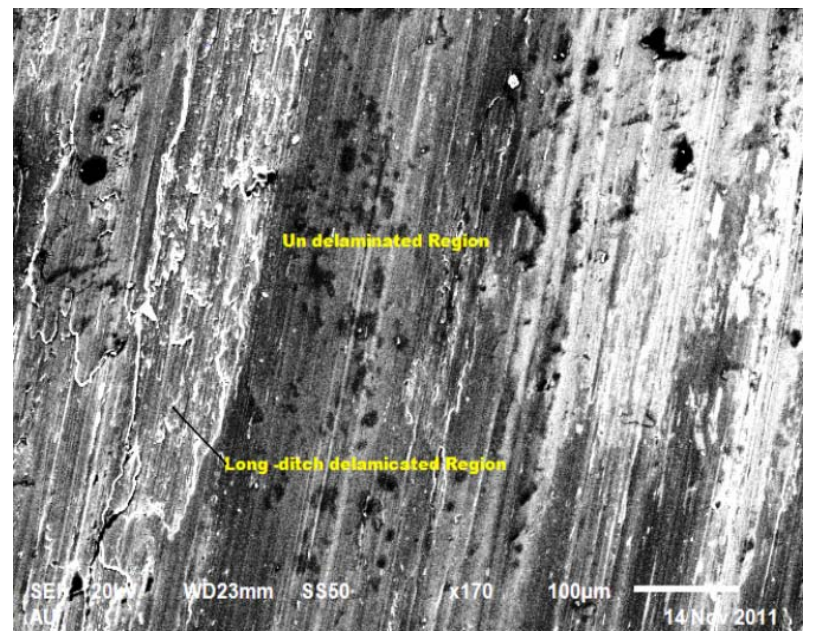

(b)

Figure 10. SEM images of wear tracks at various sliding velocities. (a) Wear track at $1 \mathrm{~m} / \mathrm{sec}$; (b) Wear track at 2 $\mathbf{m} / \mathbf{s e c}$.

\section{Microstructure;}

2) Finer wear tracks were observed without any protective oxide layer when the specimens were heat treated below the transformation temperature followed by rapid quenching and air cooling of the specimen;

3) Formation of protective oxide layer has taken place in the specimens which were heat treated above the transformation temperature followed by faster rate of cooling the alloy;

4) Shot peening and shot blasting of the specimens had resulted in obtaining higher surface roughness values which were beneficial for improving properties like bioadhesion, Osseo-integration and better fatigue strength of the implant alloys;

5) The improvement in the surface hardness of the shotpeened and shot blasted specimens has resulted in improving wear resistance of the specimen;

6) Oxidative wear has resulted in specimens tested at lower sliding speeds, where as delaminative wear has occurred at higher sliding velocities;

7) Delamination of the wear specimens has resulted in drastic improvement of hardness up to $450 \mathrm{HV}_{(0.5)}$, which has occurred due to resistance offered to plastic deformation by delaminative layers.

\section{REFERENCES}

[1] X. Y. Liu, P. K. Chu and C. X. Ding, "Surface Modification of Titanium, Titanium Alloys and Related Materials for Biomedical Applications," Journal of Materials Science and Engineering: R: Reports, Vol. 47, No. 3-4, 2004, pp. 49-121.

[2] C. J. Boehlart, C. J. Cowen, J. P. Quast, T. Akahori and M. Niinomi, "Fatigue and Wear Evaluation of Ti-Al-Nb Alloys for Biomedical Applications," Journal of Material Science \& Engineering: C, Vol. 28, No. 3, 2008, pp. 323330.

[3] U. I. Thomann and P. J. Uggowitzer, "Wear Corrosion Behavior of Biocompatible Austenitic Stainless Steel," Journal of Wear, Vol. 239, No. 1, 2000, pp. 48-58.

[4] A. Zhecheva, W. Sha, S. Malinov and A. Long, "Enhancing the Microstructure and Properties of Titanium through Nitriding and Other Surface Engineering Methods," Surface Coatings and Technology, Vol. 200, No. 7, 2005, pp. 2192-2207. doi:10.1016/j.surfcoat.2004.07.115

[5] M. Niinomi, "Mechanical Biocompatibilities of Titanium Alloys for Biomedical Applications," Journal of $\mathrm{Me}$ chanical Behavior of Biomedical Materials, Vol. 1, No. 1, 2008, pp. 30-42. doi:10.1016/j.jmbbm.2007.07.001

[6] Y. Q. Fu, N. L. Loh and A. W. Batchelor, "Improvement in Fretting and Fatigue Resistance by Application of Several Surface Treatments and Coatings," Journal of Surface and Coatings Technology, Vol. 106, No. 2-3, 1998, pp. 193-197. doi:10.1016/S0257-8972(98)00528-3

[7] A. Molinari, G. Straffelini, B. Tesi and T. Bacci, "Dry Sliding Wear Mechanisms of the Ti-6Al-4V Alloy," Journal of Wear, Vol. 208, No. 1-2, 1997, pp. 105-112. doi:10.1016/S0043-1648(96)07454-6

[8] M. O. Alam and A. S. M. A. Haseeb, "Response of Ti-6Al-4V and Ti-24Al-11Nb Alloys to Dry Sliding Wear against Hardened Steel," Journal of Tribology International, Vol. 35, No. 6, 2002, pp. 357-362.

[9] S. J. Li, R. Yang and S. Li, "Wear Characteristics of Ti-Nb-Ta-Zr and Ti-6Al-4V Alloys for Biomedical Applications," Journal of Wear, Vol. 257, No. 9-10, 2004 pp. 869-876. doi:10.1016/j.wear.2004.04.001

[10] P. Majumdar, S. B. Singh and M. Chakraborty "Wear Response of Heat Treated Ti-13-Zr-13Nb Alloy in Dry Condition and Simulated Body Fluid," Journal of Wear, Vol. 264, No. 11-12, 2008, pp. 1015-1025. doi:10.1016/j.wear.2007.08.005

[11] M. P. Gispert, A. P. Serro, R. Colaco, A. M. Botelho and D. Rego, "Tribological Behavior of Ci-Implanted Tin Coatings for Biomedical Applications," Journal of Wear, Vol. 262, No. 11-12, pp. 1337-1345.

[12] H. Guleryuz and H. Cimenglu, "Oxidation of Ti-6Al-4V 
Alloy," Journal of Alloys and Compounds, Vol. 472, No. 1-2, 2009, pp. 241-246.

[13] A. K. Jha, S. K. Singh and M. S. Kiranmayee, "Failure Analysis of Titanium Alloy (Ti-6Al-4V) Fastener in Aerospace Application," Journal of Engineering Failure Analysis, Vol. 17, No. 6, 2010, pp. 1457-1465.

doi:10.1016/j.engfailanal.2010.05.007
[14] Z. Mohammadi, A. A. Ziaei-Moayyed and A. S.-M. Mesgar, "Grit Blasting of Ti-6Al-4V Alloy: Optimization and Its Effect on Adhesion Strength of Plasma-Sprayed Hydroxyapatite Coatings," Journal of Materials Processing Technology, Vol. 194, No. 1-3, 2007, pp. 15-23.

doi:10.1016/j.jmatprotec.2007.03.119 